\title{
Prednisolone is associated with a worse lipid profile than hydrocortisone in patients with adrenal insufficiency
}

\author{
Marcus Quinkler', Bertil Ekman², Claudio Marelli³, Sharif Uddin4, Pierre Zelissen ${ }^{5}$ \\ and Robert D Murray ${ }^{6}$ on behalf of the EU-AIR Investigators
}

${ }^{1}$ Endocrinology in Charlottenburg, Berlin, Germany

${ }^{2}$ Departments of Endocrinology and Medical and Health Sciences, Linköping University, Linköping, Sweden

${ }^{3}$ Shire International GmbH, Zug, Switzerland

${ }^{4}$ Shire, Lexington, Massachusetts, USA

${ }^{5}$ Department of Internal Medicine and Endocrinology, University Medical Center Utrecht, Utrecht, the Netherlands

${ }^{6}$ Department of Endocrinology, Leeds Teaching Hospitals NHS Trust, St James's University Hospital, Leeds, UK

Correspondence

should be addressed

to M Quinkler

Email

marcusquinkler@t-online.de

\begin{abstract}
Objective: Prednisolone is used as glucocorticoid replacement therapy for adrenal insufficiency (Al). Recent data indicate that its use in $\mathrm{Al}$ is associated with low bone mineral density. Data on risk factors for cardiovascular disease in patients with $\mathrm{Al}$ treated with prednisolone are scarce, despite this condition being the predominant cause of excess mortality. We aimed to address this question using real-world data from the European Adrenal Insufficiency Registry (EU-AIR).

Design/methods: EU-AIR, comprising of 19 centres across Germany, the Netherlands, Sweden and the UK, commenced enrolling patients with $\mathrm{Al}$ in August 2012. Patients receiving prednisolone (3-6 $\mathrm{mg} /$ day, $n=50$ ) or hydrocortisone $(15-30 \mathrm{mg} / \mathrm{day}, n=909)$ were identified and grouped at a ratio of 1:3 (prednisolone:hydrocortisone) by matching for gender, age, duration and type of disease. Data from baseline and follow-up visits were analysed. Data from patients with congenital adrenal hyperplasia were excluded.

Results: Significantly higher mean \pm S.D. total $(6.3 \pm 1.6$ vs $5.4 \pm 1.1 \mathrm{mmol} / \mathrm{L} ; P=0.003)$ and low-density lipoprotein (LDL) cholesterol levels ( $3.9 \pm 1.4$ vs $3.2 \pm 1.0 \mathrm{mmol} / \mathrm{L} ; P=0.013$ ) were identified in 47 patients on prednisolone vs 141 receiving hydrocortisone at baseline and at follow-up $(P=0.005$ and $P=0.006$, respectively). HbA1c, high-density lipoprotein and triglyceride levels, body mass index, systolic and diastolic blood pressure and waist circumference were not significantly different.

Conclusions: This is the first matched analysis of its kind. Significantly higher LDL levels in patients receiving prednisolone relative to hydrocortisone could predict a higher relative risk of cardiovascular disease in the former group.
\end{abstract}

Key Words
primary adrenal
insufficiency
secondary adrenal
insufficiency
cardiovascular risk
low-density lipoprotein
cholesterol
cholesterol

Endocrine Connections (2017) 6, 1-8

\section{Introduction}

Prednisolone is a synthetic glucocorticoid that has been used over the last few decades as pharmacotherapy in a plethora of diseases due to its potent antiinflammatory and immunosuppressive properties (1). Prednisolone is absorbed rapidly after oral intake, reaching peak plasma levels within the first hour after ingestion (2).

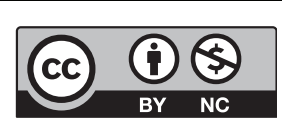

This work is licensed under a Creative Commons Attribution-NonCommercial 4.0 International License. 
The mean plasma half-life is $2-4 \mathrm{~h}(3,4)$; metabolism occurs predominantly in the liver (5) but also via the actions of renal 11/-hydroxysteroid dehydrogenase type 2 converting it into the inactive metabolite prednisone (6). Inter-individual differences in the rate of metabolism of prednisolone result in variable metabolic clearance rates, which in part, may explain the observed differences in the development of corticosteroid side effects between patients (7).

Interestingly, when the endogenous glucocorticoid, cortisol (hydrocortisone), is compared with prednisolone at the isolated human glucocorticoid receptor (GR), the transactivation activity of prednisolone is 1.7 -fold higher than that of hydrocortisone $(8,9)$. However, the biological effect of prednisolone is usually represented as 4-fold that of hydrocortisone. This observation is derived from experiments in humans investigating the dose necessary to induce negative feedback on adrenocorticotropic hormone (ACTH) secretion in hypothalamic-pituitary axis regulation (10). The discrepancy between pure receptor binding and the biological effect might be explained in part by the fact that prednisolone displays only 50\% of the affinity of cortisol for corticosteroid-binding globulin (11), resulting in relatively higher concentrations of free, unbound prednisolone. In addition, prednisolone has a higher re-activation rate from prednisone to prednisolone

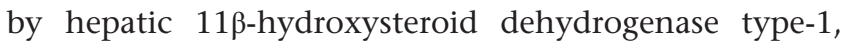
which is approximately 3-fold greater than that for cortisone to cortisol (6). This might explain the observation that orally administered prednisone shows more effective hepatic activation than cortisone, resulting in higher systemic availability of the active $11 \beta$-hydroxy form, prednisolone (12).

Prednisolone is used in some patients with adrenal insufficiency (AI) as hormone replacement therapy. Advocates of prednisolone highlight that it requires only once-daily administration, resulting in improved compliance and that it is highly cost-effective (13). In some cases, it has been used where hydrocortisone is not available (e.g., historically in the former German Democratic Republic).

In the recent Endocrine Society Clinical Practice guideline summarising therapy in AI (14), prednisolone (3-5 mg/day) is suggested as an alternative to hydrocortisone, particularly in patients with reduced compliance; however, currently, prospective studies comparing the safety and efficacy of prednisolone and hydrocortisone over time are not available. A recent review on AI stated that prednisolone should only be considered in the event of compliance problems, marked fluctuations of energy and when hydrocortisone or cortisone acetate is not tolerated (15).

As indicated by the very low level of evidence in the recent guideline, data on prednisolone in hormone replacement therapy are scarce $(16,17,18,19)$, with no available data regarding the effects on cardiovascular risk factors. Data from patients with rheumatoid arthritis on low-dose prednisolone/prednisone (defined as a dose of prednisone $<10 \mathrm{mg} /$ day) suggest a trend of increasing cardiovascular events (20).

Using data derived from the European Adrenal Insufficiency Registry (EU-AIR), we investigated relative differences in cardiovascular risk factors in patients with AI receiving hydrocortisone and prednisolone as hormone replacement therapy.

\section{Methods}

\section{Study design}

EU-AIR is an observational, open-ended study (ClinicalTrials.gov identifier: NCT01661387) in patients with primary AI (PAI), secondary AI (SAI) or congenital adrenal hyperplasia (CAH) who are undergoing longterm treatment with modified-release hydrocortisone or other glucocorticoid replacement therapies (21). The primary objective of the EU-AIR is to monitor the safety of long-term treatment with once-daily modified-release hydrocortisone and other glucocorticoid replacement therapies in patients with AI.

All enrolled patients provided written informed consent/assent. The study protocol was approved by the appropriate ethical committee in each country. Data were collected from endocrinology centres in Germany, the Netherlands, Sweden and the UK. All enrolled patients were followed during the course of routine clinical practice for the active duration of the registry. All medical care decisions, including those relating to treatment choice, are entirely at the discretion of the patient and registry physician. Patient data, including laboratory assessments, were collected by means of an electronic case report form at enrolment and thereafter at routine clinic visits (every 6-12 months) (21).

Recruitment began in August 2012; as of May 2015, 1166 patients have been enrolled. Patients with CAH and those receiving modified-release hydrocortisone were not included in the current analysis. Exposure records with a duration of less than 28 days were excluded to ensure that treatment at baseline was not related to emergency/ temporary use of medication.

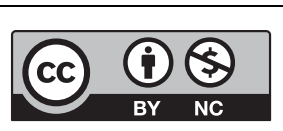

This work is licensed under a Creative Commons Attribution-NonCommercial 4.0 International License. 
Patients were grouped according to whether they had received prednisolone or hydrocortisone. To define the prednisolone group, we excluded patients receiving glucocorticoids other than prednisolone. In the hydrocortisone group, we excluded patients receiving glucocorticoids other than hydrocortisone and those receiving dual-release hydrocortisone.

\section{Matched analysis}

Patients receiving prednisolone at doses $<3 \mathrm{mg} /$ day and $>6 \mathrm{mg}$ /day in the prednisolone group were excluded from the matched analysis, thus including only those patients on doses of 3-6 mg/day, as recently recommended by the Endocrine Society guideline (14). Furthermore, patients receiving hydrocortisone at doses $<15 \mathrm{mg} /$ day and $>30 \mathrm{mg} /$ day in the hydrocortisone group were excluded, thus including only those patients receiving recommended daily doses that are also most frequently prescribed (14). These criteria identified 50 patients in the prednisolone group and 909 patients in the hydrocortisone group.

Patients receiving prednisolone and hydrocortisone were matched on estimated propensity scores (22) using greedy matching algorithm to find the nearest available match in a 1:3 ratio for age, gender, duration and type of disease (SAI or PAI). The resultant cohort consisted of 47 patients receiving prednisolone matched to 141 patients on hydrocortisone. The following variables were measured after matching: daily dose of glucocorticoid; body mass index; systolic and diastolic blood pressure; waist circumference; total cholesterol; high-density lipoprotein (HDL) cholesterol and low-density lipoprotein (LDL) cholesterol; glycated haemoglobin (HbA1c); triglycerides and the proportion of patients using statins.

\section{Statistics}

Summary statistics of continuous data and frequency counts (proportions) of categorical data were generated before and after matching to evaluate the closeness of matching. Cardiovascular risk factors between prednisolone and hydrocortisone groups were summarised using summary statistics and compared using an appropriate two-sample $t$-test at a 5\% level of significance.

\section{Follow-up data}

Data were available for 109 out of 147 patients in the hydrocortisone group at the follow-up visit
(10.0 \pm 4.9 months); all these patients continued with hydrocortisone as hormone replacement therapy. Overall, 39 out of 41 patients in the prednisolone group were still on prednisolone as hormone replacement therapy and had data available at their follow-up visit $(6.9 \pm 2.9$ months $)$.

\section{Results}

We identified 64 patients with PAI and SAI who received prednisolone as hormone replacement therapy. Baseline characteristics are shown in Table 1 . Based on the records of prednisolone use, daily doses ranged from $<2$ to $>7.5 \mathrm{mg}$ (Fig. 1). The dose range received by the most patients was $5-<6 \mathrm{mg} /$ day, which was being taken by $57.8 \%$ of patients at baseline (Fig. 1). Overall, 20.3\% of patients on prednisolone took a daily dose of $6 \mathrm{mg}$ or higher. Prednisolone was being taken once-daily by $73.4 \%$ of patients and twice-daily by $25.0 \%$ (Fig. 2).

After predefining the matching cohorts, we performed a 1:3 matching of patients on prednisolone replacement therapy to patients on hydrocortisone therapy regarding sex, age, duration and type of disease (Table 2).

The frequency of diagnosis of hypertension and diabetes mellitus was not significantly different between the two matched cohorts (Table 3). Further analysis revealed no significant differences in body mass index (BMI) and systolic or diastolic blood pressure (Table 4). There was a tendency for waist circumference to be greater in prednisolone-treated patients, but this did

Table 1 Baseline characteristics of patients with PAI and SAI from the EU-AIR $(n=64)$ receiving prednisolone as hormone replacement therapy.
Parameter

Age (years)

Female, $n(\%)$

Body mass index category, $n(\%)$

Normal $\left(18.5-<25 \mathrm{~kg} / \mathrm{m}^{2}\right)$

Overweight $\left(25-<30 \mathrm{~kg} / \mathrm{m}^{2}\right)$

Obese $\left(\geq 30 \mathrm{~kg} / \mathrm{m}^{2}\right)$

Missing data

Total cholesterol ( $\mathrm{mmol} / \mathrm{L}$ )

Low-density lipoprotein cholesterol

( $\mathrm{mmol} / \mathrm{L})$

Systolic blood pressure $(\mathrm{mmHg})$

Diastolic blood pressure $(\mathrm{mmHg})$
Duration of disease (years)
Analysis population $(n=64)$

$58.3( \pm 16.7)$

$25.0( \pm 13.1)$

40 (62.5)

$18(28.1)$

29 (45.3)

$15(23.4)$

2 (3.1)

$6.26( \pm 1.49)$

$3.85( \pm 1.27)$

$130 \pm 18$

$78 \pm 9$
Patients with congenital adrenal hyperplasia were excluded Data show mean ( \pm S.D.) unless otherwise indicated. EU-AIR, European Adrenal Insufficiency Registry; PAI, primary adrenal insufficiency; SAI, secondary adrenal insufficiency; S.D., standard deviation.

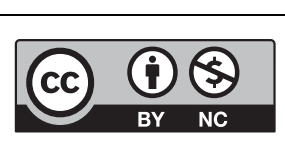

This work is licensed under a Creative Commons Attribution-NonCommercial 4.0 International License. 


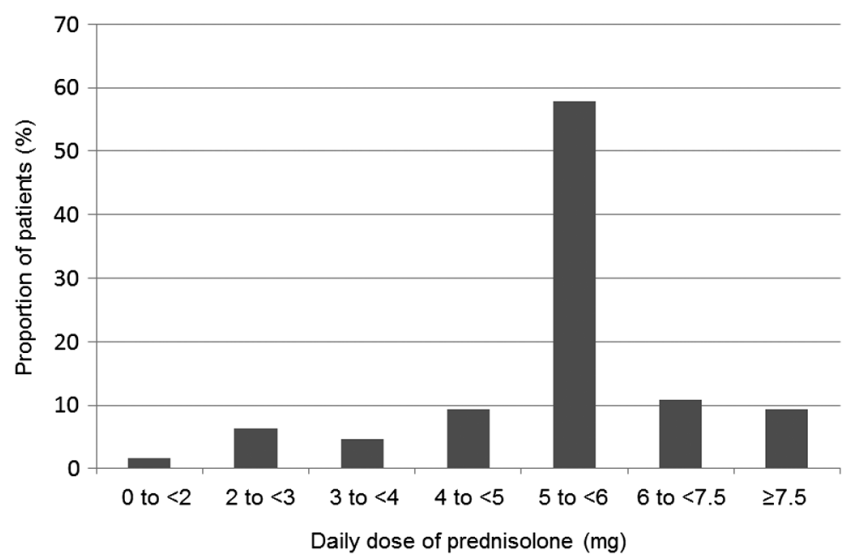

Figure 1

Daily doses of prednisolone as hormone replacement therapy in patients with primary and secondary adrenal insufficiency from the EU-AIR $(n=64)$. Patients with congenital adrenal hyperplasia were excluded. EU-AIR, European Adrenal Insufficiency Registry.

not reach statistical significance. After analysing the biochemical characteristics of the two matched cohorts, we found significantly higher total cholesterol $(P=0.003)$ and LDL cholesterol levels $(P=0.013)$ in patients receiving prednisolone vs those receiving hydrocortisone (Table 4 ). The difference in total cholesterol was significant in patients with primary and secondary AI; the difference in LDL cholesterol was significant in patients with primary AI only (Supplementary Table $1 \mathrm{a}$ and $1 \mathrm{~b}$, see section on supplementary data given at the end of this article). Statins were not prescribed in significantly different proportions in the two cohorts (Table 4).

No significant differences were seen regarding HbA1c, HDL cholesterol and triglyceride levels. After

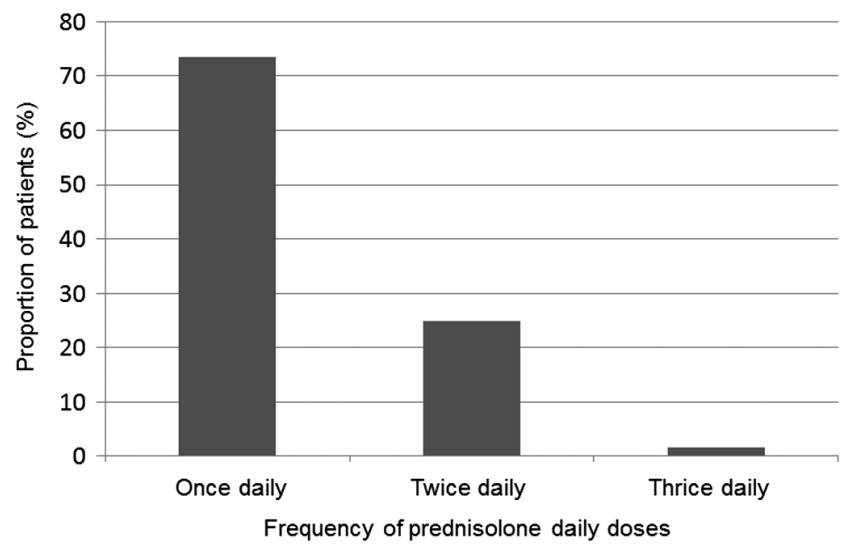

Figure 2

Frequency of prednisolone daily doses in hormone replacement therapy of patients with primary and secondary adrenal insufficiency from the EU-AIR $(n=64)$. Patients with congenital adrenal hyperplasia were excluded. EU-AIR, European Adrenal Insufficiency Registry. stratifying for gender, we observed significantly higher total and LDL cholesterol levels in prednisolone-treated vs hydrocortisone-treated women. Total cholesterol levels were significantly higher in prednisolone-treated vs hydrocortisone-treated men; the trend for LDL cholesterol failed to reach statistical significance $(P=0.179$; data not shown).

At follow-up visits, patients on hydrocortisone still showed significantly lower total and LDL cholesterol levels than those receiving prednisolone (total cholesterol: $5.3 \pm 1.1$ vs $6.0 \pm 1.3 \mathrm{mmol} / \mathrm{L}, P=0.005$; LDL cholesterol: $3.1 \pm 1.0$ vs $3.8 \pm 1.2 \mathrm{mmol} / \mathrm{L}, P=0.006)$.

\section{Discussion}

Cardiovascular disease is the major cause of mortality in the majority of developed countries (23). It is therefore important to identify patients with increased cardiovascular risk who would benefit from initiation of risk-reducing interventions. The well-established major vascular risk factors are age, sex, hypertension, smoking, dyslipidaemia and diabetes mellitus (24).

Recent retrospective epidemiological data indicate high mortality among patients with both PAI and SAI (25, $26,27,28)$. Besides adrenal crisis (29) and infectious disease (26), cardiovascular disease shows a 2 -fold increased risk for mortality in Swedish patients with PAI compared with the Swedish background population (26) and was the main cause for excess mortality in Norwegian patients with PAI (28). Cardiovascular disease has also been implicated as the primary cause for increased mortality in SAI (30). Several studies have suggested that increased vascular risk might be dependent on the daily hydrocortisone dose $(31,32)$ and the non-physiological daily profile of current glucocorticoid replacement therapy.

Comparisons between different hormone replacement regimens regarding mortality, morbidity or cardiovascular risk factors are scarce at best or even absent. Prednisolone is believed to be cost effective and efficacious, as well as requiring only once-daily administration when used for glucocorticoid replacement therapy in AI (13). Recent data, however, suggest that prednisolone is deleterious for bone mineral density in AI $(17,19,33,34)$. Few comparative data with hydrocortisone for additional steroid-dependent end points are available. Therefore, we believed that it was important to examine surrogates of vascular risk in patients with AI on prednisolone or hydrocortisone replacement therapy. This study is the first of its kind to investigate this important aspect of glucocorticoid

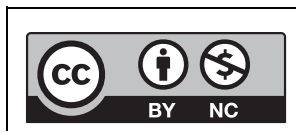

This work is licensed under a Creative Commons Attribution-NonCommercial 4.0 International License. 
Table 2 Cohorts of patients with Al from the EU-AIR with prednisolone or hydrocortisone replacement therapy used for the matching process (for age, sex, duration and type of disease (PAI or SAI)).

\begin{tabular}{|c|c|c|c|c|}
\hline \multirow[b]{2}{*}{ Variable } & \multicolumn{2}{|c|}{ Before matching } & \multicolumn{2}{|c|}{ After matching } \\
\hline & Prednisolone $(n=50)$ & Hydrocortisone $(n=909)$ & Prednisolone $(n=47)$ & Hydrocortisone $(n=141)$ \\
\hline Age (years) & $58.5(16.6)$ & $54.2(16.2)$ & $58.0(16.6)$ & $60.0(14.4)$ \\
\hline Duration of disease (years) & $25.1(13.6)$ & $15.4(11.0)$ & $23.0(10.3)$ & $23.1(10.2)$ \\
\hline Female $(\%)$ & 62.0 & 50.8 & 61.7 & 61.7 \\
\hline $\mathrm{PAI}(\%)$ & 40.0 & 30.9 & 40.4 & 40.4 \\
\hline
\end{tabular}

Data show mean ( \pm S.D.) unless otherwise indicated.

Al, adrenal insufficiency; EU-AIR, European Adrenal Insufficiency Registry; PAI, primary adrenal insufficiency; SAl, secondary adrenal insufficiency; S.D., standard deviation.

replacement. We showed clearly that prednisolone leads to an adverse lipid profile with increased total and LDL cholesterol levels. The significantly higher LDL levels in patients with AI treated with prednisolone vs those treated with hydrocortisone would predict a relative risk of 1.8 for cardiovascular disease compared with 1.3 for those patients on hydrocortisone in our cohort $(35,36,37)$.

The only similar data concerning lipid profiles in AI derive from 2424 hypopituitary patients within the KIMS database (a Pfizer International Metabolic database), prior to glucocorticoid hormone substitution (18). In that study, 1186 patients were receiving hydrocortisone (mean dose of $24.1 \mathrm{mg} /$ day), and 52 patients were receiving prednisolone (mean dose of $6.7 \mathrm{mg} /$ day). BMI did not differ between the two groups; however, waist-to-hip ratio was increased in the prednisolone group. HDL and LDL cholesterol did not differ among the two cohorts (18). No matching, however, was performed in that study, which might explain the difference compared with our observations. In the Filipsson study (18), the prednisolone cohort was older than the hydrocortisone group, and gender distribution between study groups was not equal.

Further data regarding prednisolone and cardiovascular risk are derived only from studies with patients with rheumatoid arthritis, who generally receive higher doses of prednisolone than those used in this

Table 3 Frequency of diagnoses in matched cohorts of patients with Al from the EU-AIR with prednisolone or hydrocortisone replacement therapy.

\begin{tabular}{|c|c|c|}
\hline \multirow[b]{2}{*}{ Diagnosis (\%) } & \multicolumn{2}{|c|}{ After matching } \\
\hline & $\begin{array}{l}\text { Prednisolone } \\
\qquad(n=47)\end{array}$ & $\begin{array}{l}\text { Hydrocortisone } \\
\qquad(n=141)\end{array}$ \\
\hline Hypertension & 36.2 & 35.5 \\
\hline Diabetes mellitus, all & 14.9 & 14.9 \\
\hline Diabetes mellitus type 1 & 4.3 & 0.0 \\
\hline Diabetes mellitus type 2 & 10.6 & 14.9 \\
\hline
\end{tabular}

Al, adrenal insufficiency; EU-AIR, European Adrenal Insufficiency Registry. study (>7.5 mg/day). A recent systematic literature review on cardiovascular risk induced by low-dose corticosteroids (defined as a dose of prednisone $<10 \mathrm{mg} /$ day) in rheumatoid arthritis found an association with major cardiovascular events in 4 of 6 studies; two studies did not find any significant association (20). Very recently, a 2-year open, randomised trial found a 3.7-fold increased relative risk for cerebrovascular events in patients with early rheumatoid arthritis receiving low-dose prednisolone treatment (38). However, drawing a parallel between patients with rheumatoid arthritis on prednisolone and patients with AI on prednisolone may not be valid, especially as patients with active inflammatory arthritis may have other factors that are aberrant, which may increase the risk of cardiovascular events.

In recent years, there has been improved understanding of how glucocorticoids bind to the GR and induce genomic and non-genomic effects. Genomic effects of activated GRs occur after nuclear translocation and manifest through three primary mechanisms: direct binding of GR to DNA via GR response elements and negative GR response elements to activate or repress transcription; tethering to DNA-bound transcription factors to modulate transcription indirectly; or composite activity of DNA binding and interaction with adjacent DNA-bound transcription factors to affect transcription $(39,40)$. Rapid non-genomic effects of GR ligation occur after ligand-induced dissociation of the GR multiprotein complex in the cytoplasm (39). This diversity of regulatory processes indicates that prednisolone is likely to regulate different genes than the physiological glucocorticoid, hydrocortisone (41).

This implies that the differences between the physiological effects of prednisolone and hydrocortisone do not relate simply to differences in dose equivalence. As outlined earlier, the relative biological potency and conversion rate of hydrocortisone and prednisolone were calculated using the ACTH-suppressive effect (10),

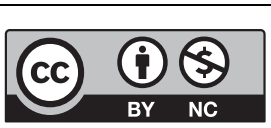


Table 4 Clinical and biochemical characteristics in matched cohorts of patients with Al from the EU-AIR with prednisolone or hydrocortisone replacement therapy.

\begin{tabular}{|c|c|c|}
\hline \multirow[b]{2}{*}{ Variable } & \multicolumn{2}{|c|}{ After matching } \\
\hline & Prednisolone $(n=47)$ & Hydrocortisone $(n=141)$ \\
\hline Daily dose (mg) & $5.0(0.6)$ & $21.5(4.8)$ \\
\hline Body mass index $\left(\mathrm{kg} / \mathrm{m}^{2}\right)$ & $27.2(3.9)(n=44)$ & $27.8(5.3)(n=119)$ \\
\hline Systolic blood pressure $(\mathrm{mmHg})$ & $128(18.1)(n=47)$ & $131(18.0)(n=133)$ \\
\hline Diastolic blood pressure $(\mathrm{mmHg})$ & $77.7(9.2)(n=47)$ & $79.4(10.2)(n=133)$ \\
\hline Waist circumference $(\mathrm{cm})$ & $99.0(13.8)(n=21)$ & $96.1(13.9)(n=86)$ \\
\hline Total cholesterol (mmol/L) & $6.3(1.6) * * *(n=36)$ & $5.4(1.1)(n=82)$ \\
\hline High-density lipoprotein (mmol/L) & $1.5(0.5)(n=31)$ & $1.5(0.4)(n=76)$ \\
\hline Low-density lipoprotein (mmol/L) & $3.9(1.4) * *(n=34)$ & $3.2(1.0)(n=71)$ \\
\hline HbA1c (\%) & $5.8(1.0)(n=32)$ & $5.8(1.0)(n=81)$ \\
\hline Triglycerides (mmol/L) & $1.8(0.8)(n=35)$ & $1.9(0.9)(n=82)$ \\
\hline Proportion of patients using statins (\%) & 25.5 & 26.9 \\
\hline
\end{tabular}

Data show mean ( \pm S.D.) unless otherwise indicated.

$* * P=0.013 ; * * * P=0.003$ (two-sample $t$-tests).

Al, adrenal insufficiency; EU-AIR, European Adrenal Insufficiency Registry; s.D., standard deviation.

resulting in a 1:4 conversion rate. However, the effects of prednisolone on eosinophils result in a conversion rate of 6:1 compared with hydrocortisone (42) and effects on growth in children with $\mathrm{CAH}$ result in a suggested conversion rate of 6-8:1 (43). Furthermore, prednisolone causes an increase in urinary nitrogen excretion and a negative nitrogen balance that was reportedly 10-17 times higher than that of hydrocortisone (42). Therefore, we believe that there is no unique whole body conversion rate between prednisolone and hydrocortisone but that this relationship is organ specific.

There are some limitations to our study, as observed in all registry based data, e.g. missing data values. The numbers of patients receiving prednisolone was relatively small; however, these numbers constitute the largest cohort of prednisolone-treated patients with AI to date.

A strength of this study is the large number of patients receiving hydrocortisone, which allowed close matching for multiple confounders between the two study cohorts. Another strength of our study is that we could provide follow-up data (via a longitudinal study) and we were able to observe the same significant differences in total and LDL cholesterol between the groups at follow-up.

In conclusion, the significantly higher LDL levels in patients with AI treated with prednisolone vs hydrocortisone suggest that prednisolone should be used with great caution as hormone replacement therapy in this condition.

\section{Supplementary data}

This is linked to the online version of the paper at http://dx.doi.org/10.1530/ EC-16-0081.

$$
\begin{aligned}
& \text { http://www.endocrineconnections.org } \\
& \text { DOI: 10.1530/EC-16-0081 }
\end{aligned}
$$

\section{Declaration of interest}

Marcus Quinkler, Bertil Ekman, Pierre Zelissen and Robert D Murray received honoraria for talks and consultancy from ViroPharma/Shire. Claudio Marelli and Sharif Uddin are employees of ViroPharma/Shire.

\section{Funding}

EU-AIR is funded by ViroPharma/Shire. This research was supported by ViroPharma/Shire.

\section{Author contribution statement}

All authors contributed to the conception of the work, and the acquisition, analysis, and interpretation of the data and drafting and revision of the manuscript. All authors meet the International Committee of Medical Journal Editors criteria for authorship for this manuscript, take responsibility for the integrity of the work as a whole and have given final approval to the version to be published.

\section{Acknowledgements}

The authors thank all participating EU-AIR centres: Bertil Ekman, Linköping, Sweden; Anna Nilsson, Gothenburg, Sweden; Pierre Zelissen, Utrecht, the Netherlands, André van Beek, Groningen, the Netherlands; Richard Feelders, Rotterdam, the Netherlands; Robert D Murray, Leeds, UK; Simon Pearce, Newcastle, UK; William Drake, London, UK; Andrew Toogood, Birmingham, UK; Peter Trainer, Manchester, UK; Ashley Grossman, Oxford, UK; Pierre-Marc Bouloux, London, UK; Marcus Quinkler, Berlin, Germany; Tina Kienitz, Berlin, Germany; Felix Beuschlein, Munich, Germany; Günter Stalla, Munich, Germany; Stefanie Hahner, Würzburg, Germany; Klaus Badenhoop, Frankfurt, Germany; and Christof Schöfl, Erlangen, Germany.

Medical writing support was provided by Noëlle L O'Regan, PhD of PharmaGenesis London, London, UK and was funded by Shire. This study was presented as an oral communication at the 18th European Congress of Endocrinology, 28-31 May 2016, Munich, Germany.

\section{References}

1 Rhen T \& Cidlowski JA. Antiinflammatory action of glucocorticoids new mechanisms for old drugs. New England Journal of Medicine 2005 353 1711-1723. (doi:10.1056/nejmra050541)

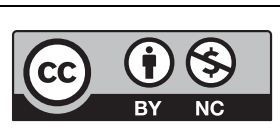

This work is licensed under a Creative Commons Attribution-NonCommercial 4.0 International License. 
2 English J, Chakraborty J, Marks V, Trigger DJ \& Thomson AG. Prednisolone levels in the plasma and urine: a study of two preparations in man. British Journal of Clinical Pharmacology 19752 327-332. (doi:10.1111/j.1365-2125.1975.tb02779.x)

3 Al-Habet S \& Rogers HJ. Pharmacokinetics of intravenous and oral prednisolone. British Journal of Clinical Pharmacology 198010 503-508. (doi:10.1111/j.1365-2125.1980.tb01796.x)

4 Derendorf H, Mollmann H, Krieg M, Tunn S, Mollmann C, Barth J \& Rothig HJ. Pharmacodynamics of methylprednisolone phosphate after single intravenous administration to healthy volunteers. Pharmaceutical Research 19918 263-268. (doi:10.102 3/A:1015864709082)

5 Hale VG \& Benet LZ. Prednisolone and prednisone exhibit linear extraction in the perfused rabbit liver. Drug Metabolism and Disposition 199119 87-93.

6 Diederich S, Eigendorff E, Burkhardt P, Quinkler M, BumkeVogt C, Rochel M, Seidelmann D, Esperling P, Oelkers W \& Bahr V. 11Beta-hydroxysteroid dehydrogenase types 1 and 2: an important pharmacokinetic determinant for the activity of synthetic mineraloand glucocorticoids. Journal of Clinical Endocrinology and Metabolism 200287 5695-5701. (doi:10.1210/jc.2002-020970)

7 Kozower M, Veatch L \& Kaplan MM. Decreased clearance of prednisolone, a factor in the development of corticosteroid side effects. Journal of Clinical Endocrinology and Metabolism 197438 407-412. (doi:10.1210/jcem-38-3-407)

8 Grossmann C, Scholz T, Rochel M, Bumke-Vogt C, Oelkers W, Pfeiffer AF, Diederich S \& Bahr V. Transactivation via the human glucocorticoid and mineralocorticoid receptor by therapeutically used steroids in CV-1 cells: a comparison of their glucocorticoid and mineralocorticoid properties. European Journal of Endocrinology 2004 151 397-406. (doi:10.1530/eje.0.1510397)

9 Diederich S, Scholz T, Eigendorff E, Bumke-Vogt C, Quinkler M, Exner P, Pfeiffer AF, Oelkers W \& Bahr V. Pharmacodynamics and pharmacokinetics of synthetic mineralocorticoids and glucocorticoids: receptor transactivation and prereceptor metabolism by 11 beta-hydroxysteroid-dehydrogenases. Hormone and Metabolic Research 200436 423-429. (doi:10.1055/s-2004-814578)

10 Khalid BA, Burke CW, Hurley DM, Funder JW \& Stockigt JR. Steroid replacement in Addison's disease and in subjects adrenalectomized for Cushing's disease: comparison of various glucocorticoids. Journal of Clinical Endocrinology and Metabolism 198255 551-559. (doi:10.1210/jcem-55-3-551)

11 Orth DN, Kovacs WJ \& Debold CR. The adrenal cortex. In Williams Textbook of Endocrinology, edn 8, pp 489-619. Eds J Wilson \& D Foster. Philadelphia, PA, USA: WB Saunders, 1992.

12 Jenkins JS \& Sampson PA. Conversion of cortisone to cortisol and prednisone to prednisolone. British Medical Journal 19672 205-207. (doi:10.1136/bmj.2.5546.205)

13 Amin A, Sam AH \& Meeran K. Glucocorticoid replacement. British Medical Journal 2014349 g4843. (doi:10.1136/bmj.g4843)

14 Bornstein SR, Allolio B, Arlt W, Barthel A, Don-Wauchope A, Hammer GD, Husebye ES, Merke DP, Murad MH, Stratakis CA, et al. Diagnosis and treatment of primary adrenal insufficiency: an Endocrine Society Clinical Practice guideline. Journal of Clinical Endocrinology and Metabolism 2016101 364-389. (doi:10.1210/ jc.2015-1710)

15 Husebye ES, Allolio B, Arlt W, Badenhoop K, Bensing S, Betterle C, Falorni A, Gan EH, Hulting AL, Kasperlik-Zaluska A, et al. Consensus statement on the diagnosis, treatment and follow-up of patients with primary adrenal insufficiency. Journal of Internal Medicine 2014275 104-115. (doi:10.1111/joim.12162)

16 Bleicken B, Hahner S, Loeffler M, Ventz M, Allolio B \& Quinkler M. Impaired subjective health status in chronic adrenal insufficiency: impact of different glucocorticoid replacement regimens. European Journal of Endocrinology $2008159811-817$ (doi:10.1530/EJE-08-0578)
17 Falhammar H, Filipsson Nystrom H, Wedell A, Brismar K \& Thoren M. Bone mineral density, bone markers, and fractures in adult males with congenital adrenal hyperplasia. European Journal of Endocrinology 2013168 331-341. (doi:10.1530/EJE-12-0865)

18 Filipsson H, Monson JP, Koltowska-Haggstrom M, Mattsson A \& Johannsson $\mathrm{G}$. The impact of glucocorticoid replacement regimens on metabolic outcome and comorbidity in hypopituitary patients. Journal of Clinical Endocrinology and Metabolism 200691 3954-3961. (doi:10.1210/jc.2006-0524)

19 Koetz KR, Ventz M, Diederich S \& Quinkler M. Bone mineral density is not significantly reduced in adult patients on low-dose glucocorticoid replacement therapy. Journal of Clinical Endocrinology and Metabolism 201297 85-92. (doi:10.1210/jc.2011-2036)

20 Ruyssen-Witrand A, Fautrel B, Saraux A, Le Loet X \& Pham T. Cardiovascular risk induced by low-dose corticosteroids in rheumatoid arthritis: a systematic literature review. Joint Bone Spine 201178 23-30. (doi:10.1016/j.jbspin.2010.02.040)

21 Ekman B, Fitts D, Marelli C, Murray RD, Quinkler M \& Zelissen PM. European Adrenal Insufficiency Registry (EU-AIR): a comparative observational study of glucocorticoid replacement therapy. BMC Endocrine Disorders 201414 40. (doi:10.1186/1472-6823-14-40)

22 D'Agostino RB Jr. Propensity score methods for bias reduction in the comparison of a treatment to a non-randomized control group. Statistics in Medicine 199817 2265-2281. (doi:10.1002/(sici)10970258(19981015)17:19<2265::aid-sim918>3.0.co;2-b)

23 Lozano R, Naghavi M, Foreman K, Lim S, Shibuya K, Aboyans V, Abraham J, Adair T, Aggarwal R, Ahn SY, et al. Global and regional mortality from 235 causes of death for 20 age groups in 1990 and 2010: a systematic analysis for the Global Burden of Disease Study 2010. Lancet 2012380 2095-2128. (doi:10.1016/S01406736(12)61728-0)

24 D'Agostino RB Sr, Pencina MJ, Massaro JM \& Coady S. Cardiovascular disease risk assessment: insights from Framingham. Global Heart 2013 8 11-23. (doi:10.1016/j.gheart.2013.01.001)

25 Bensing S, Brandt L, Tabaroj F, Sjoberg O, Nilsson B, Ekbom A, Blomqvist P \& Kampe O. Increased death risk and altered cancer incidence pattern in patients with isolated or combined autoimmune primary adrenocortical insufficiency. Clinical Endocrinology 200869 697-704. (doi:10.1111/j.1365-2265.2008.03340.x)

26 Bergthorsdottir R, Leonsson-Zachrisson M, Oden A \& Johannsson G. Premature mortality in patients with Addison's disease: a populationbased study. Journal of Clinical Endocrinology and Metabolism 200691 4849-4853. (doi:10.1210/jc.2006-0076)

27 Burman P, Mattsson AF, Johannsson G, Hoybye C, Holmer H, Dahlqvist P, Berinder K, Engstrom BE, Ekman B, Erfurth EM, et al. Deaths among adult patients with hypopituitarism: hypocortisolism during acute stress, and de novo malignant brain tumors contribute to an increased mortality. Journal of Clinical Endocrinology and Metabolism 201398 1466-1475. (doi:10.1210/jc.2012-4059)

28 Erichsen MM, Lovas K, Fougner KJ, Svartberg J, Hauge ER, Bollerslev J, Berg JP, Mella B \& Husebye ES. Normal overall mortality rate in Addison"s disease, but young patients are at risk of premature death. European Journal of Endocrinology 2009160 233-237. (doi:10.1530/EJE08-0550)

29 Hahner S, Spinnler C, Fassnacht M, Burger-Stritt S, Lang K, Milovanovic D, Beuschlein F, Willenberg HS, Quinkler M \& Allolio B. High incidence of adrenal crisis in educated patients with chronic adrenal insufficiency: a prospective study. Journal of Clinical Endocrinology and Metabolism 2015100 407-416. (doi:10.1210/ jc.2014-3191)

30 Rosen T \& Bengtsson BA. Premature mortality due to cardiovascular disease in hypopituitarism. Lancet 1990336 285-288. (doi:10.1016/0140-6736(90)91812-O)

31 Sherlock M, Reulen RC, Alonso AA, Ayuk J, Clayton RN, Sheppard MC, Hawkins MM, Bates AS \& Stewart PM. ACTH deficiency, higher doses of hydrocortisone replacement, and

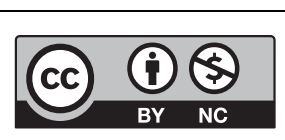

This work is licensed under a Creative Commons Attribution-NonCommercial 4.0 International License. 
radiotherapy are independent predictors of mortality in patients with acromegaly. Journal of Clinical Endocrinology and Metabolism 200994 4216-4223. (doi:10.1210/jc.2009-1097)

32 Zueger T, Kirchner P, Herren C, Fischli S, Zwahlen M, Christ E \& Stettler C. Glucocorticoid replacement and mortality in patients with nonfunctioning pituitary adenoma. Journal of Clinical Endocrinology and Metabolism 201297 E1938-E1942. (doi:10.1210/jc.2012-2432)

33 Chandy DD \& Bhatia E. Bone mineral density in patients with Addison disease on replacement therapy with prednisolone. Endocrine Practice 201622 434-439. (doi:10.4158/EP151014.OR)

34 Schulz J, Frey KR, Cooper MS, Zopf K, Ventz M, Diederich S \& Quinkler M. Reduction in daily hydrocortisone dose improves bone health in primary adrenal insufficiency. European Journal of Endocrinology 2016174 531-538. (doi:10.1530/EJE-15-1096)

35 Howard BV, Robbins DC, Sievers ML, Lee ET, Rhoades D, Devereux RB, Cowan LD, Gray RS, Welty TK, Go OT, et al. LDL cholesterol as a strong predictor of coronary heart disease in diabetic individuals with insulin resistance and low LDL: the Strong Heart Study. Arteriosclerosis, Thrombosis, and Vascular Biology 200020 830-835. (doi:10.1161/01.ATV.20.3.830)

36 Ridker PM, Rifai N, Rose L, Buring JE \& Cook NR. Comparison of C-reactive protein and low-density lipoprotein cholesterol levels in the prediction of first cardiovascular events. New England Journal of Medicine 2002347 1557-1565. (doi:10.1056/NEJMoa021993)

37 Wilson PW, D'Agostino RB, Levy D, Belanger AM, Silbershatz H $\&$ Kannel WB. Prediction of coronary heart disease using risk factor categories. Circulation 199897 1837-1847. (doi:10.1161/01. cir.97.18.1837)
38 Ajeganova S, Svensson B, Hafstrom I \& BARFOT Study Group. Low-dose prednisolone treatment of early rheumatoid arthritis and late cardiovascular outcome and survival: 10-year follow-up of a 2-year randomised trial. BMJ Open 20144 e004259. (doi:10.1136/ bmjopen-2013-004259)

39 Cain DW \& Cidlowski JA. Specificity and sensitivity of glucocorticoid signaling in health and disease. Best Practice and Research: Clinical Endocrinology and Metabolism 201529 545-556. (doi:10.1016/j. beem.2015.04.007)

40 Uhlenhaut NH, Barish GD, Yu RT, Downes M, Karunasiri M, Liddle C, Schwalie P, Hubner N \& Evans RM. Insights into negative regulation by the glucocorticoid receptor from genome-wide profiling of inflammatory cistromes. Molecular Cell 201349 158-171. (doi:10.1016/j.molcel.2012.10.013)

41 Toonen EJ, Fleuren WW, Nassander U, van Lierop MJ, Bauerschmidt S, Dokter WH \& Alkema W. Prednisolone-induced changes in geneexpression profiles in healthy volunteers. Pharmacogenomics 201112 985-998. (doi:10.2217/pgs.11.34)

42 Pechet MM, Bowers B \& Bartter FC. Metabolic studies with a new series of 1,4-diene steroids. I. Effects in addisonian subjects of prednisone, prednisolone, and the 1,2-dehydro analogues of corticosterone, desoxycorticosterone, 17-hydroxy-11desoxycorticosterone, and 9 alpha-fluorocortisol. Journal of Clinical Investigation 195938 681-690. (doi:10.1172/JCI103847)

43 Caldato MC, Fernandes VT \& Kater CE. One-year clinical evaluation of single morning dose prednisolone therapy for 21-hydroxylase deficiency. Arquivos Brasileiros de Endocrinologia and Metabologia 2004 48 705-712. (doi:10.1590/S0004-27302004000500017)

Received in final form 8 November 2016

Accepted 18 November 2016

Accepted Preprint published online 18 November 2016 http://www.endocrineconnections.org DOI: 10.1530/EC-16-0081
() 2017 The authors Published by Bioscientifica Ltd

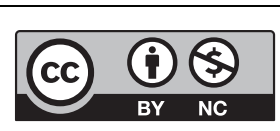

This work is licensed under a Creative Commons Attribution-NonCommercial 4.0 International License. 